\title{
INFluênCIA de SAIS E do PH dA ÁGUA NA EFICIÊnCIA DE IMAZETHAPYR + ImAzapic no ConTrole de ARROZ-Vermelho ${ }^{1}$
}

\author{
Influence of Salts and Water PH on the Efficiency of Imazethapyr + Imazapic for Red Rice \\ Control
}

\author{
SANCHOTENE, D.M. ${ }^{4}$, DORNELLES, S.H.B. ${ }^{2}$, DEBORTOLI, M.P. ${ }^{3}$, CAPITANIO, JR. ${ }^{3}$, MEZZOMO, \\ R.F. ${ }^{3}$ e GONÇALVES, R.A. ${ }^{4}$
}

\begin{abstract}
RESUMO - Na safra agrícola de 2004/2005, em Santa Maria/RS, foi realizado um experimento com o objetivo de avaliar a influência de sais e do $\mathrm{pH}$ da água de diferentes fontes de abastecimento de pulverizadores (água de fonte mineral, água de açude e água de poço artesiano) sobre a eficiência de imazethapyr $\left(75 \mathrm{~g} \mathrm{~L}^{-1}\right)+$ imazapic $\left(25 \mathrm{~g} \mathrm{~L}^{-1}\right)$ no controle de arroz-vermelho (Oryza sativa). No preparo da calda para pulverização do herbicida, foi utilizada água na sua condição original e água acidificada com ácido cítrico até pH 4,5. Foi verificado que os tratamentos com água de $\mathrm{pH}$ 4,5 proporcionaram maior eficiência da mistura (imazethapyr + imazapic) no controle do arroz-vermelho do que com águas alcalinas ( $\mathrm{pH} 9,4$ e 8,7 ). Todos os tratamentos herbicidas causaram intoxicação às plantas do arroz cultivado. Entretanto, nos tratamentos em que se utilizou água alcalina, foi observada recuperação mais rápida das plantas de arroz, cultivar IRGA 422 CL.
\end{abstract}

Palavras-chave: arroz-vermelho, controle, dureza da água, Oryza sativa.

\begin{abstract}
This research was carried out in Santa Maria/RS during the 2004/2005 crop season to evaluate the influence of salts and water $\mathrm{pH}$ on different sources of spray suppliers (mineral water, dam water and artesian well water) on imazethapyr (75 $\left.\mathrm{g} \mathrm{L}^{-1}\right)+$ imazapic (25 $\left.\mathrm{g} \mathrm{L}^{-1}\right)$ efficiency in red rice control. Thus, water under original condition and acidified water with citric acid to $\mathrm{pH}$ 4,5 have been used to prepare the herbicide solutions. It has been verified that the treated plots with water at $p H 4,5$ showed better action of imazethapyr $\left(75 g^{L^{-1}}\right)+$ imazapic $\left(25 g^{L^{-1}}\right)$ in the red rice control than alkaline water with $\mathrm{pH} 9,4$ and 8,7. All the treatments with herbicide presented intoxication in the rice. Nevertheless, the treatments with alkaline water showed a fast recuperation in rice plants (IRGA $422 \mathrm{CL}$ ).
\end{abstract}

Keywords: red rice, control, water hardness, Oryza sativa.

A qualidade da água utilizada na calda de pulverização influencia o desempenho dos agroquímicos. Essa característica pode ser abordada sob dois aspectos: a qualidade química da água ( $\mathrm{pH}$, sais e íons dissolvidos) e a qualidade fisica (presença de argila e matéria orgânica) (Theisen \& Ruedell, 2004). Com relação aos aspectos químicos, trabalhos publicados demonstram que a água alcalina ( $\mathrm{pH}$ acima de $7,0)$ ou a presença de alguns compostos utilizados em nutrientes foliares na calda podem diminuir a eficiência dos herbicidas, especialmente de dessecantes à base de glyphosate, de alguns herbicidas inibidores da enzima aceto lactato sintetase (ALS) e de inibidores da enzima acetil coenzima A carboxilase

1 Recebido para publicação em 9.10.2006 e na forma revisada em 17.4.2007.

2 Professor Assistente - Setor de Botânica. Dep. de Biologia. Universidade Federal de Santa Maria, prédio 16, sala 3260, Campus/ Camobi. Santa Maria-RS, ${ }^{3}$ Engo-Agro - Pesquisador vinculado ao Grupo Interdisciplinar de Pesquisa e Herbologia, Setor de Botânica, Dep. de Biologia, Universidade Federal de Santa Maria, prédio 16, Laboratório 3121, Campus/Camobi, 97105900 - Santa Maria-RS; ${ }^{4}$ Acadêmico de Agronomia. Universidade Federal de Santa Maria, <dmartisan@ mail.ufsm.br>.Autor para correspondência. 
(ACCAse) (Mervosh \& Balke, 1991; Nalejava \& Matysiak, 1993).

Em muitos casos, observa-se que a redução do $\mathrm{pH}$ da calda para valores próximos de 4,5 e a utilização de água limpa são práticas que podem aumentar a eficiência dos herbicidas (Souza \& Velloso, 1996), pelo fato de a absorção foliar e sua atividade dependerem do estado das moléculas sobre as quais o $\mathrm{pH}$ da solução tem influência. Além do $\mathrm{pH}$, a dureza da água também pode afetar a estabilidade da calda, pois águas captadas em zonas rurais geralmente apresentam uma série de sais em dissolução. A dureza da água tem relação com a presença de sais, principalmente carbonato de cálcio $\left(\mathrm{CaCO}_{3}\right)$. Os principais íons causadores de dureza são $\mathrm{Ca}^{++}$e $\mathrm{Mg}^{++}$originados de carbonatos e bicarbonatos, bem como cloretos, sulfatos e nitratos (Buhler \& Burnside, 1983). Águas duras diminuem a eficiência dos herbicidas ao reagirem com os surfatantes aniônicos (principalmente $\mathrm{K}^{+}$e $\mathrm{Na}^{+}$), através de substituições químicas que geram precipitados e floculações.

Herbicidas como glyphosate, 2,4-D amina, paraquat, sethoxydim, clethodim, bentazon, chlorimuron-ethyl e imazethapyr podem ter sua eficiência afetada quando aplicados com águas duras e calda com $\mathrm{pH}$ alcalino. Souza \& Velloso (1996) afirmam que os herbicidas do grupo químico das imidazolinonas, especialmente imazethapyr e imazapyr, têm sua absorção foliar aumentada quando o pH da água utilizada na preparação da calda está na faixa de 4,0 a 4,5 . Isso também é observado para outros herbicidas, como o glyphosate.

O movimento dos herbicidas inibidores de ALS, como o imazethapyr, ocorre através da cutícula por um processo de difusão. Certas propriedades físico-químicas do herbicida (Leite et al., 1998) e a interação das moléculas deste com elementos químicos presentes na água utilizada como veículo (Souza \& Velloso, 1996) podem favorecer ou não a absorção e, por conseqüência, influenciar o resultado do controle do alvo biológico. O mecanismo fundamental de absorção dos inibidores de ALS ocorre pelo sistema de "armadilha iônica", uma vez que esses produtos são ácidos fracos com pKa (constante de ionização) entre 1,9 e 4,8 , estando sujeitos à ionização em função do gradiente em que se encontram (Leite et al., 1998). As máximas absorção e eficiência de herbicidas com caráter ácido ocorrem em valores de $\mathrm{pH}$ em que $50 \%$ das moléculas se encontram dissociadas (McCormick, 1990). Além disso, em $\mathrm{pH}$ baixo, a taxa de hidrólise alcalina é reduzida, tendo como vantagem o aumento da velocidade de absorção do herbicida (Theisen \& Ruedell, 2004).

No sistema de produção de arroz irrigado denominado de "Clearfield", utilizam-se cultivares de arroz tolerantes aos herbicidas do grupo químico das imidazolinonas, sendo eles, portanto, dependentes desses herbicidas. No Brasil está registrado o herbicida Only ${ }^{\circledR}$, cujos componentes são imazethapyr (75 gramas do ingrediente ativo por litro de produto comercial) e imazapic ( 25 gramas do ingrediente ativo por litro de produto comercial).

Em razão da falta de informações sobre a influência da qualidade química da água utilizada no preparo da calda, na eficiência de imazethapyr + imazapic no controle de arrozvermelho e na sua seletividade à cultura do arroz irrigado (cultivar IRGA $422 \mathrm{CL}$ ), instalouse um experimento na safra 2004/2005 em área localizada no distrito de Arroio Grande, município de Santa Maria-RS. O delineamento experimental utilizado foi o de blocos ao acaso com seis tratamentos herbicidas e dois tratamentos testemunhas, com quatro repetições. Os tratamentos consistiram em seis tipos de calda em mistura com imazethapyr + imazapic e duas testemunhas sem herbicida: a primeira capinada e a segunda infestada (Tabela 1). Cada unidade experimental apresentou dimensões de $3 \times 6 \mathrm{~m}\left(18 \mathrm{~m}^{2}\right)$, sendo considerados os $10 \mathrm{~m}^{2}$ centrais da parcela como área útil para fins de avaliação.

No dia anterior à aplicação dos tratamentos, foram coletados três tipos de água (de fonte mineral, de açude e de poço artesiano), nas quantidades necessárias para a pulverização. A água foi coletada em fontes comumente utilizadas para abastecimento de pulverizadores. Em laboratório da Universidade Federal de Santa Maria (UFSM), foi determinado o $\mathrm{pH}$ das águas coletadas, medido através de equipamento com voltímetro eletrônico digital e eletrodo de vidro. A água da fonte mineral (fonte 1) foi coletada no município de Caçapava do SulRS, em estância hidromineral. O pH original 
Tabela 1 - Tratamentos aplicados para controle de arroz-vermelho (Oryza sativa) na cultura do arroz irrigado cultivar IRGA 422 CL. UFSM, Santa Maria-RS, 2004/2005

\begin{tabular}{|c|c|c|}
\hline Tratamento & $\begin{array}{c}\text { Dose } \\
\left(\mathrm{mL} \mathrm{ha}^{-1}\right)\end{array}$ & Fonte e tipo de água adicionada à calda \\
\hline 1. $(\text { imazethapyr }+ \text { imazapic })^{1 /}+\mathrm{DASH}^{2 /}$ & $1000+0,5 \% \%^{3 /}$ & Água mineral com $188,2 \mathrm{ppm}$ de $\mathrm{CaCO}_{3}$ e pH 9,4 \\
\hline 2. (imazethapyr + imazapic) + DASH & $1000+0,5 \%$ & Água mineral com $188,2 \mathrm{ppm}$ de $\mathrm{CaCO}_{3}$ acidificada até $\mathrm{pH} 4,5$ \\
\hline 3. (imazethapyr + imazapic) + DASH & $1000+0,5 \%$ & Água de açude com 19,3 ppm de $\mathrm{CaCO}_{3}$ e pH 5,1 \\
\hline 4. (imazethapyr + imazapic) + DASH & $1000+0,5 \%$ & Água de açude com 19,3 ppm de $\mathrm{CaCO}_{3}$ acidificada até pH 4,5 \\
\hline 5. (imazethapyr + imazapic) + DASH & $1000+0,5 \%$ & Água de poço artesiano com 84,7 ppm de $\mathrm{CaCO}_{3}$ e pH 8,7 \\
\hline 6. (imazethapyr + imazapic) + DASH & $1000+0,5 \%$ & Água de poço artesiano com $84,7 \mathrm{ppm}$ de $\mathrm{CaCO}_{3}$ acidificada até $\mathrm{pH} 4,5$ \\
\hline 7. Testemunha capinada & - & - \\
\hline 8. Testemunha infestada & - & - \\
\hline
\end{tabular}

desta água foi de 9,44 e a concentração inicial de $\mathrm{CaCO}_{3}$, determinada no Laboratório de Química Analítica do Centro de Ciências Naturais e Exatas da UFSM, de 188,2 ppm, classificada como "muito dura", devido à alta concentração de sais, conforme escala proposta em Nielsen Technical Trading, citado por Theisen \& Ruedell (2004). A água de açude (fonte 2) apresentou $\mathrm{pH}$ inicial de 5,1 e 19,3 ppm de $\mathrm{CaCO}_{3}$ (considerada "leve"). A água de poço artesiano (fonte 3 ) apresentou $\mathrm{pH} 8,7$ e 84,7 ppm de $\mathrm{CaCO}_{3}$ (considerada "moderadamente dura"). As águas de açude e de poço artesiano foram coletadas na Granja São Carlos de Loreta, no município de Santa Maria-RS.

Antes da inclusão do herbicida à calda, nos tratamentos 2, 4 e 6 (Tabela 1) foi adicionado ácido cítrico $0,1 \mathrm{~mol} \mathrm{~L}^{-1}$ (previamente padronizado) à água, através de titulação potenciométrica, até que o $\mathrm{pH}$ permanecesse constante em 4,5. Imediatamente após a acidificação da água, preparou-se a calda com adição do herbicida Only ${ }^{\circledR}$ e também do adjuvante mineral DASH na proporção de $0,5 \% \mathrm{v} / \mathrm{v}$ (tratamentos 1 a 6). Os frascos com as caldas foram imediatamente transportados para a área experimental em caixa térmica. Para aplicação dos tratamentos, utilizou-se pulverizador costal pressurizado a $\mathrm{CO}_{2}$ com barra de $2,5 \mathrm{~m}$ munida com seis pontas XR Teejet 100.02 espaçadas entre si $0,5 \mathrm{~m}$. No momento da pulverização a temperatura do ar foi de $25,3{ }^{\circ} \mathrm{C}$, com umidade relativa de $59,7 \%$ e velocidade do vento de
2,6 $\mathrm{km} \mathrm{h}^{-1}$ (determinadas através do equipamento Kestrel 3000). No momento da aplicação as plantas de arroz-vermelho apresentavam duas a três folhas. A inundação da área ocorreu 72 horas após a aplicação dos tratamentos.

O efeito dos herbicidas sobre o arroz-vermelho foi determinado pelo método qualitativo, caracterizado por avaliações visuais baseadas em escala arbitrária estabelecida. Foi empregada escala percentual para controle de arrozvermelho e seletividade à cultura, utilizando como padrão as testemunhas. As avaliações foram feitas aos 10, 20 e 30 dias após a aplicação, utilizando-se a escala percentual, em que 0 significou ausência de controle de arrozvermelho ou de sintoma de toxidez nas plantas de arroz e 100, controle total das plantas de arroz-vermelho ou a morte de todas as plantas de arroz.

Os valores percentuais de controle de arroz vermelho e de intoxicação às plantas de arroz irrigado foram submetidos à transformação angular Arcosen " $x / 100$ e análise da variância pelo teste $\mathrm{F}$. A comparação das médias transformadas foi efetuada pelo teste de Duncan a 5\% de probabilidade.

Os resultados apresentados na Tabela 2 permitem verificar que os tratamentos em que a água foi acidificada proporcionaram maior controle de arroz-vermelho que o obtido nos tratamentos em que a água utilizada na calda foi mantida com o pH original (tratamentos 1, 
Tabela 2 - Médias de controle de arroz-vermelho (Oryza sativa) por tratamentos herbicidas e seletividade ao cultivar de arroz IRGA 422 CL. UFSM, Santa Maria-RS, 2004/2005

\begin{tabular}{|c|c|c|c|c|c|c|c|}
\hline \multirow[b]{2}{*}{ Tratamento } & \multirow{2}{*}{$\begin{array}{c}\text { Dose } \\
\left(\mathrm{mL} \mathrm{ha}^{-1}\right)\end{array}$} & \multicolumn{3}{|c|}{ Controle $(\%)$} & \multicolumn{3}{|c|}{ Intoxicação (\%) } \\
\hline & & $\begin{array}{c}10 \\
\text { DAA }^{6}\end{array}$ & $\begin{array}{c}20 \\
\text { DAA }\end{array}$ & $\begin{array}{c}30 \\
\text { DAA }\end{array}$ & $\begin{array}{c}10 \\
\text { DAA }\end{array}$ & $\begin{array}{c}20 \\
\text { DAA }\end{array}$ & $\begin{array}{c}30 \\
\text { DAA }\end{array}$ \\
\hline $\begin{array}{l}\text { 1. (imazethapyr+imazapic) }{ }^{\mathrm{1}^{\prime}}+\mathrm{DASH}^{2 /}+\text { água } \\
\text { de fonte mineral com } 188,2 \mathrm{ppm} \text { de } \\
\mathrm{CaCO}_{3} \mathrm{e} \mathrm{pH} 9,4\end{array}$ & $1000+0,5 \%{ }^{3 /}$ & $85 c^{4}$ & $90 c^{4}$ & $89 \mathrm{c}$ & $16 b$ & $8 b$ & $0 \mathrm{c}$ \\
\hline $\begin{array}{l}\text { 2. (imazethapyr+imazapic)+DASH+água } \\
\text { com } 188,2 \mathrm{ppm} \text { de } \mathrm{CaCO}_{3} \text { acidificada até } \\
\mathrm{pH} 4,5\end{array}$ & $1000+0,5 \%$ & $92 b$ & $98 \mathrm{a}$ & $99 \mathrm{a}$ & $25 \mathrm{a}$ & $14 \mathrm{a}$ & $5 b$ \\
\hline $\begin{array}{l}\text { 3. (imazethapyr+imazapic)+DASH+água de } \\
\text { açude com } 19,3 \text { ppm de } \mathrm{CaCO}_{3} \text { e pH 5,1 }\end{array}$ & $1000+0,5 \%$ & $84 c$ & $88 \mathrm{c}$ & $90 \mathrm{c}$ & $18 \mathrm{~b}$ & $4 \mathrm{c}$ & $0 \mathrm{c}$ \\
\hline $\begin{array}{l}\text { 4. (imazethapyr + imazapic)+DASH+água } \\
\text { de açude com } 19,3 \mathrm{ppm} \text { de } \mathrm{CaCO}_{3} \\
\text { acidificada até } \mathrm{pH} 4,5\end{array}$ & $1000+0,5 \%$ & $90 \mathrm{~b}$ & $95 b$ & $97 \mathrm{ab}$ & $26 a$ & $12 \mathrm{a}$ & $7 \mathrm{a}$ \\
\hline $\begin{array}{l}\text { 5. (imazethapyr+imazapic)+DASH+água de } \\
\text { poço artesiano com } 84,7 \text { ppm de } \mathrm{CaCO}_{3} \mathrm{e} \\
\text { pH } 8,7\end{array}$ & $1000+0,5 \%$ & $79 d$ & $86 \mathrm{c}$ & $88 \mathrm{c}$ & $15 b$ & $3 c$ & $0 \mathrm{c}$ \\
\hline $\begin{array}{l}\text { 6. (imazethapyr+imazapic)+DASH+água de } \\
\text { poço artesiano com } 84,7 \text { ppm de } \mathrm{CaCO}_{3} \\
\text { acidificada até pH 4,5 }\end{array}$ & $1000+0,5 \%$ & $89 b$ & $96 a b$ & $95 b$ & $25 \mathrm{a}$ & $15 \mathrm{a}$ & $5 b$ \\
\hline 7. Testemunha capinada & - & $100 \mathrm{a}$ & $98 \mathrm{a}$ & $98 \mathrm{a}$ & $0 \mathrm{c}$ & $0 \mathrm{~d}$ & $0 \mathrm{c}$ \\
\hline 8. Testemunha infestada & & $0 \mathrm{~d}$ & $0 \mathrm{~d}$ & $0 \mathrm{~d}$ & $0 \mathrm{c}$ & Od & $0 \mathrm{c}$ \\
\hline $\mathrm{CV}(\%)$ & - & 3,08 & 4,29 & 3,56 & 8,19 & 18,20 & 20,17 \\
\hline
\end{tabular}

${ }^{1 /}$ Imazethapyr $75 \mathrm{~g} \mathrm{~L}^{-1}+$ imazapic $25 \mathrm{~g} \mathrm{~L}^{-1} ;{ }^{2 /} \mathrm{DASH}$ - óleo mineral (adjuvante); ${ }^{3 /}$ Dosagem de adjuvante em relação ao volu me da calda. ${ }^{4}$ Médias seguidas pela mesma letra na coluna não diferem estatisticamente pelo teste de Duncan a 5\% de probabilidade. $5 /$ Nos tratamentos 1,3 e 5 a água utilizada para formação da calda herbicida manteve o pH original. ${ }^{6 /}$ Dias após aplicação.

3 e 5). Esses resultados corroboram aqueles citados por Souza \& Velloso (1996) para o herbicida imazethapyr aplicado sobre plantas daninhas de folha larga na cultura da soja. Os pesquisadores verificaram maior controle das plantas daninhas quando utilizaram água com $\mathrm{pH} 4,0$ no preparo da calda, e controle menor com águas alcalinas. Esse fato deve-se à maior absorção do herbicida em pH baixo (Shaner, 1989). Águas alcalinas que apresentam ions e sais de $\mathrm{Ca}^{++}$e $\mathrm{Mg}^{++}$, entre outros, afetam a eficiência dos herbicidas, desestabilizando as formulações por se ligarem às moléculas dos ingredientes ativos (Theisen $\&$ Ruedell, 2004).

Todos os tratamentos herbicidas causaram intoxicação às plantas do arroz cultivado IRGA $422 \mathrm{CL}$, com amarelecimento da lâmina foliar e do colmo variando de leve a moderado. Foi observado que, nos tratamentos em que a água foi acidificada, os danos foram mais expressivos que nos demais e as folhas permaneceram maior tempo com os sintomas de amarelecimento. Isso demonstra que a acidificação da calda proporcionou maior absorção do herbicida tanto pelas plantas do arroz-vermelho como pelas do arroz cultivado, que é tolerante a imazethapyr + imazapic, concordando com o observado por Vargas \& Roman (2003), os quais concluíram que a acidificação da calda reduz a dissociação das moléculas. Assim, herbicidas dissolvidos em condições de baixo $\mathrm{pH}$ são absorvidos com maior facilidade pelas plantas, pelo fato de as moléculas se encontrarem na forma não-dissociada. Nos tratamentos em que a água foi mantida com o $\mathrm{pH}$ original até a formação da calda, a recuperação das plantas do arroz cultivado foi mais rápida: aos 30 dias após a aplicação dos tratamentos, não mais apresentavam os sintomas visuais de intoxicação.

No tratamento 1 com alta concentração de sais (188,5 ppm - água muito dura) foi verificado que o controle de arroz-vermelho foi igual ao do tratamento 5 com concentração de sais menor (84,7 ppm - água moderadamente dura), demonstrando que o fator limitante à 
menor eficiência de controle foi o $\mathrm{pH}$ alcalino dessas caldas - de 9,7 e 8,4, respectivamente - quando comparado aos tratamentos acidificados.

Os resultados obtidos no experimento permitem concluir que a eficiência de imazethapyr + imazapic é afetada pelo $\mathrm{pH}$ da água utilizada na aplicação - neste estudo, a acidificação da água até $\mathrm{pH} 4,5$ potencializou o controle de arroz-vermelho - e que para imazethapyr + imazapic a acidificação da calda pode ser importante em nivel de campo.

\section{LITERATURA CITADA}

BUHLER, D. D.; BURNSIDE, O. C. Effect of water quality, carrier volume and acid on ghlyphosate phytotoxicity. Weed Sci., v. 31, p. 163-169, 1983.

LEITE, C. R. F.; ALMEIDA, J. C. V.; PRETE, C. E. C. Aspectos fisiológicos, bioquímicos e agronômicos dos herbicidas inibidores da ALS (AHAS). Londrina:

Grafmark, 1998. 68 p.
McCORMICK, R. W. Effects of $\mathrm{CO}_{2}, \mathrm{~N}_{2}$, air and nitrogen salts on spray solution pH. Weed Technol., v. 6, p. 322327, 1990.

MERVOSH, T. L.; BALKE, N. E. Effects of calcium, magnesium and phosphate on glyphosate absorption by cultured plant cells. Weed Sci., v. 39, p. 347-353, 1991.

NALEJAWA, J. D.; MATYSIAK, R. Optmizing adjuvants to overcome glyfosate antagonistic salts. Weed Sci., v. 7, p. 299-324, 1993.

SHANER, D. L. Factors affecting soil and foliar bioavaibility of imidazolinones. Princeton: Cyanamid, 1989. $24 \mathrm{p}$

SOUZA, R. O.; VELlOSO, J. A. R. O. Tecnologia na aplicação de herbicidas. In: SOUZA, R. O.; VELLOSO, J. A. R. O. (Eds.). Tecnologia e segurança na aplicação de produtos fitossanitários. Santa Maria: Universidade Federal de Santa Maria, 1996. p. 41-53.

THEISEN, G.; RUEDELL, J. Tecnologia de aplicação de herbicidas: teoria e prática. Passo Fundo: Aldeia Norte, 2004. $90 \mathrm{p}$.

VARGAS, L.; ROMAN, E. S. Controle de plantas daninhas em pomares. Bento Gonçalves: 2003. 9 p. (Circular Técnica 47). 